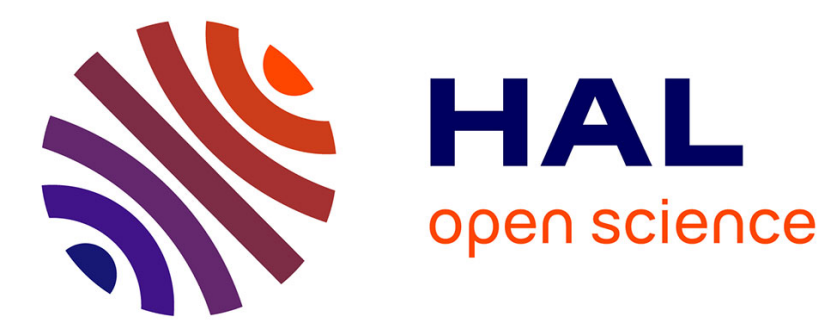

\title{
23. Effet tunnel dans des jonctions In-PbTe
}

\author{
V.C. Kieu, R. Granger, C. Fink
}

\section{To cite this version:}

V.C. Kieu, R. Granger, C. Fink. 23. Effet tunnel dans des jonctions In-PbTe. Revue de Physique Appliquée, 1970, 5 (6), pp.908-908. 10.1051/rphysap:0197000506090800 . jpa-00243493

\section{HAL Id: jpa-00243493 https://hal.science/jpa-00243493}

Submitted on 1 Jan 1970

HAL is a multi-disciplinary open access archive for the deposit and dissemination of scientific research documents, whether they are published or not. The documents may come from teaching and research institutions in France or abroad, or from public or private research centers.
L'archive ouverte pluridisciplinaire HAL, est destinée au dépôt et à la diffusion de documents scientifiques de niveau recherche, publiés ou non, émanant des établissements d'enseignement et de recherche français ou étrangers, des laboratoires publics ou privés. 


\title{
23. EFFET TUNNEL DANS DES JONCTIONS In-PbTe
}

\author{
V. C. KIEU, R. GRANGER et C. FINK
}

Laboratoire de Physique des Solides, C. N. R. S., 92, Bellevue, France

Après un bref exposé des procédés d'élaboration des jonctions In-PbTe on insistera sur certains détails qui ont permis d'obtenir des jonctions "propres ", les caractéristiques $I(V), \mathrm{d} I / \mathrm{d} V(V)$ et $\mathrm{d}^{2} I / \mathrm{d} V^{2}$ seront présentées. La discussion des résultats conduit à proposer un modèle de barrière de potentiel de ces jonctions et permet d'expliquer la nature des pics des courbes $\left(\mathrm{d}^{2} I / \mathrm{d} V^{2}\right)(V)$. 